\title{
Enteral Detoxication in Complex Treatment of Acute Intestinal Obstruction
}

\author{
Shavkat Karimov ${ }^{1}$, Sayfiddin Baymakov ${ }^{2}$, Asqar Asrarov ${ }^{3}$ \\ Farobi-2, Almazar District, Department of General Surgery, Tashkent Medical Academy, Tashkent, Uzbekistan
}

\begin{abstract}
Acute intestinal obstruction is remaining one of the actual problems of urgent surgical diseases. Therefore, the aim of this research was the improvement of the results of treatment of patients with acute intestinal nontumoral obstruction by means of determining of the role and significance of enterosorption in complex of enteral measures for prevention bacterial translocation and endotoxicosis on 63 patients with acute intestinal obstruction. Complex treatment was complete with using of enterosorption in main group. Specific content of intestinal and abdominal fluid microflora was investigated for studying of phenomenon of bacterial translocation. The using of enteral measures in complex treatment of patients with acute intestinal obstruction with addition of domestic preparation "Zerotox" promoted to improvement of microflora and prevention of bacterial translocation of intestinal flora and permitted to significantly decrease number of postoperative complications (from 20 to $7,9 \%$ ) and mortality (from 8 to $2,6 \%)$.
\end{abstract}

Keywords: acute intestinal obstruction, intestinal failure syndrome, bacterial translocation, enteral measures, enterosorption, zerotox

\section{Introduction}

Acute intestinal obstruction (AIO) is one of the most actual problems of surgery. High lethality of this pathology, which reaches $17-21 \%$ and doesn't tend to decrease $[1,3,5]$, is in most cases caused by the development of a severe endotoxemia and the related multiorgan disorders[2,4,9]. In spite of the fact that the main method of treatment of patients with AIO is surgical intervention, it is not always possible to save a patient $[5,6,8]$.

According to many experts $[1,2,5]$, the severity of local and system inflammatory reaction and the development of the endogenous intoxication (EI) are defined by the syndrome of intestinal insufficiency (SII). SII in this contingent of patients is formed long before operation and includes disorders of all functions of the digestive and transport conveyor (motor, secretory, absorptive, and barrier functions of intestines) $[3,4,6]$. Paresis of intestines and disorders of intestinal contents transit while increasing intra intestinal pressure, sharply change the quantity and quality of intraluminal and parietal intestinal micro flora, break barrier function of intestines and con-tribute to translocations of toxins and microorganisms in the bloodstream and peritoneal cavity $[2,5,10]$. In this regard, the value of the digestive tract (DT) as the initial and potential source of endogenous intoxication of the bacterial and dismetabolic nature be-comes obvious [7-9].

At the present stage of surgical treatment of AIO, many scientists [3, 5], while paying great attention to an intraoperative transnasal intubation of intestines and a decompression along with mechanical removal from a gleam of a small intestine of toxic connections, consider it expedient to apply enteral actions supplementing them with the intestinal lavage (IL) and an enterosorbtion in the early postoperative period $[7,10]$. Preparations of sorption and detoxication effect of different nature are used for this purpose. In recent years the information about preparation "zerotoks" appeared - a domestic production made from a natural product - hydrolytic lignin of cotton seeds peel which possesses high adsorptive ability not only to toxic products of exogenous and endogenous origin, but also to pathogenic bacteria with their subsequent destruction [9]. We have not found any data about the use of this preparation in surgical practice.

In this regard, the purpose of our work has been the improvement of treatment results of patients with AIO by defining the role and place of an enterosorbtion by zerotoks in a complex with the enteral actions for the prevention of a bacterial translocation and an endotoxemia.

\section{Material and Methods of Research}

We studied the results of treatment of 63 patients aged from 16 to 83 years with AIO of non-neoplastic genesis, hospitalized in surgical department of the $3^{\text {rd }}$ clinic of the Tashkent Medical Academy in years 2008-2015. Patients were from 16 till 83 , most of them of working-age $(68.2 \%)$, 10 patients $(15,8 \%)$ were older than 60 years.

The adhesive intestinal obstruction observed in 35 patients $(55.6 \%)$ was the most frequent cause of AIO. It is also necessary to note that adhesive process in 31 patients served as the reason of enteric obstruction and only in 4 - colonic. In 2 of $3(3,2 \%)$ patients the cause of AIO was the intussusception of a small intestine into large intestine, in 1 - ileoileal intussusception.

Strangulative intestinal obstruction was diagnosed in 18 $(28.6 \%)$ patients, including at 13 with volvulus (in 9 sigmoid volvulus, in 3 volvulus of the small intestine on the background of adhesions, in 1 patient - nodulation is revealed in the background of a minor adhesions). In 1 of 5 patients with stomach hernias, hernia was internal. The reason of obstructive intestinal impassability which was in 7 (11.1\%) patients, was foreign matters - in 2 (28.6\%), gallstones and bezoar - in $5(71.4 \%)$.

All patient after the statement of the diagnosis carried out a complex of the conservative medical actions directed on elimination of AIO. Unsuccessfulness of these actions 


\section{International Journal of Science and Research (IJSR) \\ ISSN (Online): 2319-7064 \\ Index Copernicus Value (2013): 6.14 | Impact Factor (2015): 6.391}

within two hours served as the indication to performance of the emergency surgery. The choice of surgery depended on an operational finds and the reason of AIO.

The colliotomy made in $29(46 \%)$ patient was the most frequent type of surgery. In $6(20,7 \%)$ patients the intestines resection with "side-to-side" type anastomosis was carried out. Besides, the resection of intestines was also made in 7 $(11,1 \%)$ patients in connection with a necrosis (gangrene) of intestines. In all cases a small intestine was resected with imposing of an interintestinal "side-to-side" type anastomosis: $1(14,3 \%)$ with an nodulation, $1(14,3 \%)$ - with an intussusception, $2(28,6 \%)$ - with small intestine volvulus, $2(35,7 \%)$ - with the restrained hernia, $1(7,1 \%)-$ with a foreign matter of a small intestine. In $3(4,8 \%)$ patients the intestines resection in connection with a necrosis of large intestine (volvulus of the colon with perforation and foreign matter in 1) and a necrosis of invaginated part of a small intestine was done. (Ileocolic intussusception).

In 27 (42,8\%) patients with AIO was followed by peritonitis of various degree of prevalence: diffusion peritonitis was found in $23(36,5 \%)$ patients, poured - in $4(6,3 \%)$. The serous exudate was noted in $10(37 \%)$ patients, serous fibrinous - in $13(48,1 \%)$, purulent - in $4(14,9 \%)$.

Depending on the used medical actions, patients were divided into 2 groups: the control group was made of 25 patients without enterosorbtion, the main group included 38 patients at whom the enterosorbent "zerotoks" (production of Uzbek Scientific-Research Chemical- Pharmaceutical Institute named after A. Sultanov, Tashkent) was applied [9].

In control group the treatment was carried out by the traditional technique accepted in clinic: in the early postoperative period - the active intestines decompression (ID) and IL through the two-channel naso-intestinal probe established during operation. IL was carried out by drop introduction of $1500 \mathrm{ml}$ of salt solution (identical on the electrolytic structure to a himus of a small intestine) through a small gleam of a naso-intestinal probe, with an exposition of 30 minutes and the subsequent active aspiration.

Patients of the main group received a similar complex of medical actions with an enterosorbtion. For this purpose a suspension at the rate of $100 \mathrm{~g}$ of zerotoks powder on 1000 $\mathrm{ml}$ of $0,9 \%$ of solution of chloride of sodium was prepared . Enterosorbtion was begun after active aspiration of contents of a small intestine with drop introduction to a nasointestinal probe of an enterosorbent. The single volume of a sorbent made $500 \mathrm{ml}$. After injection of a preparation, an exposition within 30 minutes was created, then active aspiration from a big gleam of a probe was carried out. Further series of an enterosorbtion were carried out each 8 hours ( 3 times per day) in the office of intensive therapy or in recovery room. In the rest of the time the naso-intestinal probe was in the DK mode. Duration of series of an enterosorbtion was 3-5 days depending on the level of the endogenous intoxication (EI), a state of motor-evacuation function of the gastrointestinal tract, the general health of patients. In process of restoration of motor-evacuation function of the gastrointestinal tract and eliminations of manifestations of SII, it was changed to enteral probe food or the gentle oral food.

The standard clinical, laboratory, microbiological and instrumental methods (an electrocardiogram, ultrasonography, a X-ray analysis) were applied for the assessment of efficiency of the carried-out treatment, confirmations of SII and a syndrome of endogenous intoxication. Special attention was paid on feature of a course of a disease and the postoperative period.

Observation over a condition of physical activity of a gastrointestinal tract in patients in the early postoperative period was made by means of dynamic x-ray control and method of a peripheral poly electro-enterography according to D. Sobakin (1995). The last one was carried out by the device EGS-4m with the special filters which are built in it allowing to write down bioelectric activity of various parts of a gastrointestinal tract.

Before operation and also in the early postoperative period, for an objective assessment of a condition of patients, the degree of EI was estimated based on the leukocyte index of intoxication (LII) by a technique of Kalf-Kalifa, concentration of toxins of molecules of average weight (MAW) by N. I. Gabrielyan's technique and cowriter in modification A. S. Vladyki and cowriters. (1986) and to the level of products of a nitrogenous exchange (urea, creatinine).

For studying of a phenomenon of a bacterial translocation in patients with AIO, the specific structure of intestinal contents micro flora and exudate of an abdominal cavity is studied. Material was taken away during operation and in the 1-, 3-, 5-and 7 days of the postoperative period. A quantitative assessment of the content of microorganisms in various environments of an organism with the use of the sector Gould method on high-selective nutrient mediums was carried out. (Feldman U.M. . etc.//Lab. business. 1984).

\section{Results and Discussion}

Blood pressure of patients of both groups at receipt was below "normal rate" on average for 10-15 mm. CVP indicators in all patients were equal to zero, tachycardia (on average 102 $\pm 9,5$ BPM was noted). High losses of water and electrolytes were reflected in the general blood test where the haemo concentration picture was observed: the level of hemoglobin in average was $84 \pm 8,8 \mathrm{~g} / 1$, hematocrit $47 \pm 2,1 \%$. These indicators and also results of a biochemical blood test testified to initial-ly serious condition of patients.

A stage-by-stage aspiration of contents of gastrointestinal tract was carried out intraoperatively during installation of naso-intestinal probe. The average size of gastrointestinal tract reached $1860 \pm 34 \mathrm{ml}$.

One of the indicators of elimination of SII and safe postoperative period during AIO was the emergence of intestinal peristalsis. Thus, in patients with mild endotoxemia, peristaltic waves appeared on the 3rd day after operation, and with severe degree with favorable condition only on 5-6th days of the postoperative period. 


\section{International Journal of Science and Research (IJSR) \\ ISSN (Online): 2319-7064 \\ Index Copernicus Value (2013): 6.14 | Impact Factor (2015): 6.391}

Intraoperative aspiration of contents of swollen intestine loops with the help of a naso-intestinal probe, and also its continuation in the early postoperative period in combination with IL promoted early appearance of intestinal peristalsis. Thanks to these actions indicators of an endotoxemia authentically decreased (tab. 1).

Table 1: Indicators of severity of endotoxemia in patients with AIO after operation

\begin{tabular}{|c|c|c|c|c|c|c|}
\hline \multirow{2}{*}{$\begin{array}{c}\text { Term of research, } \\
\text { days }\end{array}$} & \multicolumn{2}{|c|}{ LII } & \multicolumn{2}{c|}{$\boldsymbol{M A} \boldsymbol{W}$} & \multicolumn{2}{c|}{ Urea } \\
\cline { 2 - 7 } & Control gr. & Main gr. & Control gr. & Main gr. & Control gr. & Main gr. \\
\hline Initially & $7,4 \pm 0,91$ & $7,8 \pm 0,78$ & $1,6 \pm 0,11$ & $1,5 \pm 0,12$ & $13,9 \pm 1,3$ & $12,4 \pm 1,5$ \\
\hline 1 & $6,8 \pm 0,84^{*}$ & $6,1 \pm 1,2^{*}$ & $1,6 \pm 0,32^{*}$ & $1,4 \pm 0,38^{*}$ & $13,1+1,1^{*}$ & $11,2 \pm 1,3^{*}$ \\
\hline 3 & $3,2 \pm 0,82^{*}$ & $2,5 \pm 0,94^{*}$ & $1,2 \pm 0,17^{*}$ & $0,9 \pm 0,18^{*}$ & $8,9 \pm 0,81^{*}$ & $8,2 \pm 0,88^{*}$ \\
\hline 5 & $1,2 \pm 0,66$ & $1,4 \pm 0,46$ & $0,76 \pm 0,18^{*}$ & $0,7 \pm 0,17^{*}$ & $7,2 \pm 0,78^{*}$ & $7,6 \pm 0,72^{*}$ \\
\hline 7 & $1,05 \pm 0,05$ & $1,03 \pm 0,05$ & $0,58 \pm 0,15$ & $0,52 \pm 0,14$ & $7,7 \pm 0,38$ & $7,8 \pm 0,56$ \\
\hline
\end{tabular}

Note. * - $\mathrm{P}<0,05$ compared with the previous observed day.

The microbiological researches of quantitative parameters of microorganisms from material of intestinal contents conducted during operation revealed a picture of a dysbiosis whose characteristic was a reliable reduction of quantity of anaerobic flora and essential increase of facultative flora (tab. 2).

In 24 hours after operation, disbiotic processes in intestines became severe. Thus, the quantity of lactobacilli decreased by 5 . In facultative group of microbes, Escherichia increased by 3 . On the 3 rd day after the operation the positive changes affecting both an-aerobic, and facultative group of microbes were registered in flora of intestines. On the 5 th day after the operation in flora of intestines the positive changes arose, which became most expressed on the 7th day, and exactly in these terms we see elimination of staphylococcus and protea. It is known that exactly these microbes provide development of pyoinflammatory complications be-cause of their enzymes of pathogenicity.

In exudate of an abdominal cavity during microbiological research during operation lactobacilli, peptostreptococci, an Escherichia, staphylococcus, en-terococci, proteas and Candida sort of fungi were found in the indigenous representatives of the intestinal microflora (tab. 3). It testifies that the walls of intestines become permeable for microorganisms during AIO (a horizontal bacterial translocation). On the 1 st day after the operation, all abovementioned types of microflora of exudate were found, however the quantity of this flora was slightly more than at the previous examination. The quantity of lactobacilli decreased twice. On the 3rd day after operation a considerable change of a microbic landscape, anaerobic and aerobic bacteria were found in the studied exudate during microbiological research. Certain reduction of quantity of enterococcus, escherichias, protea and fungi was noted. In the exudate withdrawn on the 5th day after the operation, micro-organisms almost were not observed.

In 5 patients $(20 \%)$ generally with severe degree of an endotoxemia, post-operative complications were observed, whose reason, in our opinion, consisted in slow decrease level in the EI in these patients, despite the ID and IL which were carried out in the postoperative period.

It should be noted that the decrease in an endotoxemia was also achieved by parenteral introduction of various electrolytic solutions, proteinaceous and protein-freeof blood substitutes and means for parenteral food. Despite this, general condition of patients, especially with initially severe endotoxemia, improved slowly. The general condition of patients, especially those with initially heavy endotoxe-mia, improved slowly.

2 patients of control group died because of multiorgan insufficiency.

The analysis of results of complex treatment of patients with AIO with inclusion of a naso-intestinal intubation, carrying out in the postoperative active period ID and IL showed a validity of use of the last one. The postoperative complications which became the reason of failures were observed in patients with initially serious condition and a severe endotoxemia. Medical actions held were obviously insufficient for decrease in the EI level and elimination of manifestations of SII that was a cause of death of patients. All this induced us to search of more effective remedies for treatment of patients.

The addition of a complex of the enteral medical actions in the early postoperative period with an enterosorbtion in the patients who are in more serious condition led to noticeable positive changes. According to results of a poly electroenterograph, the emergence of active peristaltic waves in most of patients of the main group was noted on average on the 2-3rd days, and the peristaltic waves approached to norm - on the 4th day after operation.

Along with it, in patients of the main group progressive reduction separated from a naso-intestinal probe and objective confirmation of emergence of a satisfactory vermicular movement of intestines (poly electroenterograph) in earlier terms was observed. Noticeable decrease in indicators of EI and manifestations of SII was caused also by carrying out an enterosorbtion (tab. 1).

Intestinal microflora after application of an enterosorbent considerably improved on the 3rd day after carrying out operation. Thus, against increase in quantity of anaerobic bacteria the maintenance of aerobic bacteria considerably decreased. Lactobacilli, staphylococcus, streptococci and proteas were not found. Exudate was absent on the 5th day after operation, unlike patients without application of an enterosorbent (tab. 2, 3).

The analysis of postoperative complications showed that due to such differentiated approach to treatment of AIO in the main group postoperative complications arose only in 3 


\section{International Journal of Science and Research (IJSR) ISSN (Online): 2319-7064 \\ Index Copernicus Value (2013): 6.14 | Impact Factor (2015): 6.391}

$(7,9 \%)$ patients, one patient died $(2,6 \%)$ of a myocardial infarction.

Thus, in patients suffering from AIO, dysbiosis microflorae develops in intestines whose characteristic is reliable reduction of quantity of anaerobic flora and increase in facultative flora. In exudate of abdominal cavity, especially in the presence of peritonitis, in all patients the microbic contamination was found that testified the process of generalization, namely a bacterial translocation. Therefore, this mechanism plays large role in development of AIO and leads to degenerate and dystrophic changes of tissues of organs with their subsequent insufficiency. SII and EI are the leading factors in pathogenesis of development of AIO therefore treatment, including surgery and enteral actions (ID and IL and enterosorbtion), have to be directed on their decrease and elimination. The addition to complex treatment with enteral medical actions with use of a domestic enterosorbent of a zerotoks promoted intestinal microflora improvement, interfered with a translocation of bacterial flora from intestines, thereby considerably reduced the number of postoperative complications (with 20 to 7,9\%) and a lethality (with 8 to $2,6 \%$ ). Carrying out the above actions at this contingent of patients, being a preparatory stage, creates favorable conditions for additional nutritive support of disorders of metabolic processes of an organism in the most physiologic enteral way..

\section{Conclusions}

In prevention and elimination of EI, SII and a translocation of bacterial flora of intestines at surgical treatment of patients with AIO, the essential role belongs to carrying out the enteral actions: ID, IL, and enterosorbtion. The use of medical actions in a complex with enteral actions with domestic enterosorbent zerotoks promotes intestinal microflora improvement, interferes with a translocation of bacterial flora from intestines due to what the number of postoperative complications (from 20 to 7,9\%) and a lethality considerably decreases (from 8 to $2,6 \%$ ).

\section{References}

[1] Vorobey A.V., Shuleyko A.Ch., Lurye V. N. The ways of improvement of treatment results in patients with enteric obstruction //Surgery. - 2012. - № 10. - P. 35 39.

[2] Gostishev V.K. Bacterial translocation in accute intestinal obstruction//Medicine and ecology. - 2015. №1. - P. 57-61.

[3] Karimov M.R. Sindrome of functional intestinal insufficiency in patients with acute mechanical intestinal obstruction and the way of its correction: Abstract. Thesis. ... Candidate of medical sciences. Tashkent, 2009. - 18 p.

[4] Mukhamedov I.M. Micro ecology of the most important biotopes of a body of the person. - Tashkent, 2007. - 437 p.

[5] Parenteral and enteral nutrition: National management; under the editorship of M. Sh. Hubutiya, T.S. Popov, A.I. Saltanov. - M.: GEOTAR-Media, 2014. 800 p.

[6] Bacterial translocation in the critically ill - evidence and methods of prevention Review article / M. Gatt, B.S. Reddy, J. Macfie // Aliment. Pharmacol. Ther. 2007. - Vol. 25. - P. 741-757.

[7] Chang Hwan Choi, Sae Kyung Chang The role of small intestinal overgrowth in functional gastrointestinal disorders // J. Neurogastroenterol. Mot. - 2016. - Vol. 22. - P. 3-5.

[8] Diagnosis of small intestinal bacterial overgrowth in the clinical practice / M. Gabrielli, G. D'angelo, T. Dirienzo, E. Scarpellini, V. Ojetti // Europ. Rev. Med. Pharmacol. Sci. - 2013. - Vol. 17 (Suppl 2). - P. 3035.

[9] Ismailova M.G., Yunuskhodjaeva Kh.G., Ismailova P.L., Boyko I.B. Physical-Chemical and Pharmacological Research on New Lignin Enterosorbent // J. Pharm. Pharmacol. - 2014. - Vol. 2. - P. 642-651.

[10] Small intestinal bacterial overgrowth syndrome // Jan Bures, Jiri Cyrany, Darina Kohoutova et al. // Wld J. Gastroenterol. - 2010. - Vol. 16 (24). - P. 2978-2990.

Table 2: Intestinal flora indicators in patients with AIO before and after operation $(\lg (\mathrm{M} \pm \mathrm{m}) \mathrm{CFU} / \mathrm{ml})$

\begin{tabular}{|c|c|c|c|c|c|c|c|c|c|c|}
\hline \multirow{4}{*}{ Group of microbes } & \multicolumn{10}{|c|}{ Quantity of microbes in 1 мл } \\
\hline & \multirow{3}{*}{ Norm } & \multirow{3}{*}{$\begin{array}{l}\text { During } \\
\text { operation }\end{array}$} & \multicolumn{8}{|c|}{ Days after operation } \\
\hline & & & \multicolumn{2}{|c|}{1} & \multicolumn{2}{|c|}{3} & \multicolumn{2}{|c|}{5} & \multicolumn{2}{|c|}{7} \\
\hline & & & control & Main & control & main & control & main & control & main \\
\hline $\begin{array}{c}\text { Total number of } \\
\text { anaerobes }\end{array}$ & $10,2 \pm 0,30$ & $7,30 \pm 0,2$ & $6,15 \pm 0,3$ & $6,25 \pm 0,3$ & $6,30 \pm 0,4$ & $6,90 \pm 0,4$ & $7,80 \pm 0,5$ & $7,80 \pm 0,5$ & $9,00 \pm 0,4$ & $9,50 \pm 0,4$ \\
\hline Lactobacilli & $7,6 \pm 0,20$ & $4,10 \pm 0,3$ & $2,60 \pm 0,1$ & $3,10 \pm 0,1$ & $5,10 \pm 0,3$ & $5,20 \pm 0,3$ & $4,30 \pm 0,2$ & $5,30 \pm 0,2$ & $5,80 \pm 0,2$ & $6,90 \pm 0,2$ \\
\hline Bifidobacteria & $8,8 \pm 0,30$ & $5,20 \pm 0,3$ & $3,30 \pm 0,1$ & $3,80 \pm 0,1$ & $4,60 \pm 0,2$ & $4,80 \pm 0,2$ & $5,30 \pm 0,3$ & $5,30 \pm 0,3$ & $6,70 \pm 0,3$ & $7,50 \pm 0,3$ \\
\hline Peptostreptococcus & $1,3 \pm 0,10$ & $1,60 \pm 0,1$ & $2,85 \pm 0,1$ & $2,05 \pm 0,1$ & $2,00 \pm 0,1$ & $1,80 \pm 0,1$ & $2,00 \pm 0,1$ & $1,00 \pm 0,1$ & $2,15 \pm 0,1$ & 0 \\
\hline $\begin{array}{c}\text { Total number of } \\
\text { aerobes }\end{array}$ & $7,6 \pm 0,25$ & $8,10 \pm 0,4$ & $8,20 \pm 0,4$ & $8,00 \pm 0,4$ & $7,80 \pm 0,5$ & $7,85 \pm 0,5$ & $6,30 \pm 0,5$ & $7,90 \pm 0,5$ & $7,00 \pm 0,4$ & $7,00 \pm 0,4$ \\
\hline LP Escherichia & $6,5 \pm 0,15$ & $2,30 \pm 0,1$ & $2,60 \pm 0,1$ & $3,60 \pm 0,1$ & $3,15 \pm 0,2$ & $3,85 \pm 0,2$ & $3,00 \pm 0,1$ & $5,00 \pm 0,1$ & $5,10 \pm 0,3$ & $6,10 \pm 0,3$ \\
\hline LN Escherichia & $1,5 \pm 0,10$ & $4,60 \pm 0,2$ & $4,50 \pm 0,1$ & $3,40 \pm 0,1$ & $2,60 \pm 0,1$ & $2,20 \pm 0,1$ & $3,30 \pm 0,2$ & $2,00 \pm 0,2$ & $3,00 \pm 0,1$ & $1,00 \pm 0,1$ \\
\hline Staphylococcus & $2,1 \pm 0,14$ & $3,15 \pm 0,1$ & $4,0 \pm 0,15$ & $4,00 \pm 0,15$ & $4,15 \pm 0,2$ & $3,15 \pm 0,2$ & $3,00 \pm 0,1$ & $2,00 \pm 0,1$ & 0 & 0 \\
\hline Streptococci & $1,2 \pm 0,10$ & $2,60 \pm 0,1$ & $2,30 \pm 0,1$ & $2,10 \pm 0,1$ & $2,00 \pm 0,1$ & $1,50 \pm 0,1$ & $2,00 \pm 0,1$ & 0 & $1,60 \pm 0,1$ & 0 \\
\hline Enterococci & $4,3 \pm 0,20$ & $5,10 \pm 0,3$ & $4,15 \pm 0,2$ & $4,05 \pm 0,2$ & $4,30 \pm 0,2$ & $4,50 \pm 0,2$ & $4,60 \pm 0,2$ & $4,60 \pm 0,2$ & $4,00 \pm 0,2$ & $4,60 \pm 0,2$ \\
\hline Proteas & $2,1 \pm 0,10$ & $4,60 \pm 0,2$ & $3,45 \pm 0,2$ & $3,00 \pm 0,2$ & $3,00 \pm 0,1$ & $2,80 \pm 0,1$ & $2,80 \pm 0,1$ & $1,80 \pm 0,1$ & 0 & 0 \\
\hline Fungus. Candida & $2,0 \pm 0,10$ & $3,60 \pm 0,2$ & $3,00 \pm 0,1$ & $3,20 \pm 0,1$ & $3,10 \pm 0,1$ & $3,00 \pm 0,1$ & $3,15 \pm 0,1$ & $2,15 \pm 0,1$ & $3,00 \pm 0,1$ & $2,00 \pm 0,1$ \\
\hline
\end{tabular}




\section{International Journal of Science and Research (IJSR) \\ ISSN (Online): 2319-7064 \\ Index Copernicus Value (2013): 6.14 | Impact Factor (2015): 6.391}

Table 3: The characteristic of microflora of abdominal cavity exudate in patients with AIO before and after operation

\begin{tabular}{|c|c|c|c|c|c|c|c|c|c|c|}
\hline \multirow{4}{*}{ Microorganisms } & \multicolumn{10}{|c|}{ Quantity of microbes in 1 мл exudate } \\
\hline & \multirow{3}{*}{ Norm } & \multirow{3}{*}{$\begin{array}{l}\text { During } \\
\text { operation }\end{array}$} & \multicolumn{8}{|c|}{ Days after operation } \\
\hline & & & \multicolumn{2}{|c|}{1} & \multicolumn{2}{|c|}{3} & \multicolumn{2}{|l|}{5} & \multicolumn{2}{|c|}{7} \\
\hline & & & control & main & control & main & control & main & control & main \\
\hline Lactobacilli & \multirow{8}{*}{ 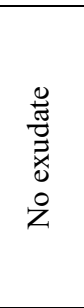 } & $2,00 \pm 0,10$ & $1,0 \pm 0,1^{*}$ & $1,0 \pm 0,1^{*}$ & 0 & 0 & 0 & \multirow{8}{*}{ 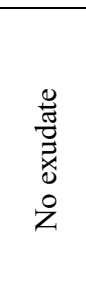 } & \multirow{8}{*}{ 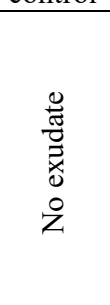 } & \multirow{8}{*}{ 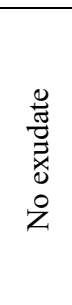 } \\
\hline Peptostreptococcus & & $1,00 \pm 0,01$ & $2,0 \pm 0,11^{*}$ & $1,8 \pm 0,11^{*}$ & $1,30 \pm 0,10^{*}$ & $1,00 \pm 0,10^{*}$ & 0 & & & \\
\hline Escherichia & & $3,00 \pm 0,11$ & $2,00 \pm 0,1^{*}$ & $2,00 \pm 0,1^{*}$ & 0 & $1,30 \pm 0,10^{*}$ & 0 & & & \\
\hline Staphylococcus & & $3,15 \pm 0,12$ & $2,60 \pm 0,12$ & $2,20 \pm 0,12$ & $1,30 \pm 0,10^{*}$ & 0 & $1,0 \pm 0,01$ & & & \\
\hline Streptococci & & $2,60 \pm 0,10$ & $1,85 \pm 0,1$ & $1,65 \pm 0,1$ & $1,00 \pm 0,01^{*}$ & 0 & 0 & & & \\
\hline Enterococci & & $2,15 \pm 0,11$ & $1,60 \pm 0,10$ & $1,40 \pm 0,10$ & $1,00 \pm 0,01^{*}$ & $0,90 \pm 0,01^{*}$ & $1,10 \pm 0,1$ & & & \\
\hline Proteas & & $1,00 \pm 0,01$ & $1,30 \pm 0,1$ & $1,30 \pm 0,1$ & $1,10 \pm 0,10$ & $1,10 \pm 0,10$ & 0 & & & \\
\hline Fungus. Candida & & $1,00 \pm 0,01$ & $1,15 \pm 0,1$ & $1,10 \pm 0,1$ & $1,00 \pm 0,10$ & $0,90 \pm 0,10$ & $1,15 \pm 0,1$ & & & \\
\hline
\end{tabular}

Note. *- $\mathrm{P}<0,05$ in comparison with indicators in day of operation. 